\title{
Two Accounts of the Problem of Enhanced Control
}

\author{
DAMIR ČIČIĆ* \\ Belgrade, Serbia
}

\begin{abstract}
According to event-causal libertarianism, an action is free in the sense relevant to moral responsibility when it is caused indeterministically by an agent's beliefs, desires, intentions, or by their occurrences. This paper attempts to clarify one of the major objections to this theory: the objection that the theory cannot explain the relevance of indeterminism to this kind of freedom (known as free will). Christopher Evan Franklin (2011, 2018) has argued that the problem of explaining the relevance of indeterminism to free will (which he calls "the problem of enhanced control") arises because it is difficult to see how indeterminism could enhance our abilities, and disappears when we realize that beside the relevant abilities free will requires opportunities. In this paper, I argue that the problem occurs not because of the focus on abilities, but because of the difficulty to explain how indeterminism could contribute to the satisfaction of the sourcehood condition of free will in the framework of event-causal theory of action.
\end{abstract}

Keywords: free will, indeterminism, control, event-causal libertarianism, ability to do otherwise, alternative possibilities, sourcehood.

\section{Introduction}

According to the 'standard version' of event-causal libertarianism, a person acts with free will when the person's action is caused indeter-

* I would like to express my deep gratitude to Professor Gary Watson for his encouragement and conversations about the ideas I present here. I would also like to thank Professor Taylor Cyr, Dr. Maria Sekatskaya, and Dr. Münir Cem Kayaligil for their comments on earlief $r$ versions of this paper. 
ministically (and non-deviantly ${ }^{1}$ ) by his or her mental states of the relevant kind (his or her desires, beliefs, intentions or their occurrences). ${ }^{2}$ This theory is appealing to many philosophers because it combines incompatibilism (the thesis that free will requires the falsity of determinism) with a metaphysically modest theory of human agency-the event-causal theory. ${ }^{3}$ However, many philosophers find it problematic, among other reasons, because it seems unable to explain adequately the relevance of indeterminism to free will (control necessary for moral responsibility) (Pereboom 2001: 49; Clark 2003). According to eventcausal libertarian theory, agents in deterministic worlds don't have free will because of determinism, even if their actions are caused by their beliefs and desires. However, if the causal relations between their mental states and actions are indeterministic - the theory says - their actions are free actions. Many critics find this claim difficult to accept. They find it incredible that mere chance in the causal relation between one's mental states and actions could account for the difference between an unfree and a free action. They ask the following question: how could the mere possibility of an agent's mental states causing an alternative decision entail that the agent exercised more control (than he or she would have exercised otherwise) in making the decision he or she actually made?

Christopher Evan Franklin $(2011,2018)$ has offered an interesting reply to this challenge which he named "the problem of enhanced control". According to Franklin, critics of event-causal libertarianism are right that indeterminism by itself cannot enhance control: no one has more control simply because it is possible that he or she will do otherwise. However, in his view, indeterminism is not the only difference between free and unfree agency on event-causal libertarian theory. For in virtue of indeterminism, he argues, event-causal libertarian agents

${ }^{1}$ A piece of behavior could be caused by an agent's mental states in a way that undermines its being a free and intentional action. Thus, an agent may desire very much to do something and believe that she can do it by moving her body in a certain way, and that desire and belief could cause her body to move in that way. However, the relevant bodily movement would not be an intentional and free action if it were caused by the desire and belief via a causal chain which involves a reflex reaction of the agent's motor system triggered by the agent's excitement at the prospect of performing the action in question (see Davidson 1980: 78-79).

${ }^{2}$ Another version of this theory locates indeterminism in the processes that give rise to beliefs and desires (see Clarke 2003: Ch. 4).

${ }^{3}$ This is so because it explains free action in terms of the causal relations between events, which is the dominant way of explaining processes in nature, and because causation is widely regarded as a relation between events. In contrast, the agent-causal libertarian theory, according to which free actions are caused directly by agents as substances, is regarded by many philosophers as obscure and empirically implausible, or even as incoherent (Clark 2003: Ch. 10; Pereboom 2001: Ch. 3). For arguments in favor of the agent-causal theory see Taylor (1966) and O'Connor (2000). For arguments in favor of event-causal libertarianism see (Kane 1996; Balaguer 2004; Mele 2006: Ch. 5; Van Inwagen 1983: 137-50;). 
have the opportunity to do otherwise which compatibilist agents lack. ${ }^{4}$ This is significant, he claims, because the opportunity in question allows the former agents to exercise their ability to do otherwise and thus control how their lives unfold. ${ }^{5}$ In his view, critics have failed to notice this due to their focus on abilities: not being able to see how indeterminism could provide new abilities, they concluded that indeterminism constitutes the only difference between event-causal libertarianism and compatibilism, and that indeterminism per se enhances control according to the former theory.

However, is the focus on abilities really what has led the critics to this conclusion? And, can the problem of enhanced control be solved by invoking the opportunity to do otherwise? I argue in this paper that the answers to these questions are negative. I argue that the problem of enhanced control does not arise because of the focus on abilities in general, or the ability to do otherwise in particular, but because it is not clear how indeterminism by itself, or via indeterministic alternative possibilities (ability and opportunity to do otherwise), contributes to the satisfaction of the sourcehood condition of free will-the condition which says that in order to have free will one must be an appropriate source of action. ${ }^{6}$

I begin my discussion of the problem of enhanced control by presenting Harry Frankfurt's famous argument against the relevance of alternative possibilities to moral responsibility. I do that because his argument rests on certain assumptions about free will-assumptions involving sourcehood-that, in my view, give rise to this problem. By considering event-causal libertarianism in the light of those assumptions, I provide an account of the problem that puts emphasis on the notion of sourcehood. ${ }^{7}$ Next, I compare my account with Franklin's

${ }^{4}$ Franklin provides an argument for the incompatibility of determinism and the opportunity to do otherwise which he calls "The No Opportunity Argument" (Franklin 2011: 699-705). Van Miltenburg and Ometto (2016: 9-11) present an objection to his argument.

${ }^{5}$ Franklin suggests that the word "free" in the expression "free will" refers to the relevant opportunity, whereas "will" refers to the relevant ability (or abilities) (Franklin 2018: 60).

${ }^{6}$ The problem in the focus of this paper is an instance of a "general problem of enhanced control" that threatens any theory of free will in which mere indeterminism makes a difference between free and unfree agency. Richard Taylor's agent-causal libertarian theory, for example, is a theory of this type. Consequently, it faces the problem of enhanced control too (see Gary Watson 2004b: 193-194). My analysis of the problem as applied to event-causal libertarianism was inspired by Gary Watson's thesis that any theory which considers alternative possibilities and sourcehood (self-determination in Watson's terminology) as logically independent conditions, is bound to fail (Watson 2004b: 193).

${ }^{7}$ What exactly is the sourcehood condition? As I mentioned above, it is a condition according to which free will requires that one is, or that one has the power to be, an appropriate source of action (in the sense relevant to freedom and responsibility). But what does that mean? Perhaps the best way to answer this question involves giving examples of failures to be such a source. It is clear, for instance, that when one moves as a result of being pushed by another person or does something as a result of 
(in key respects) and argue that my account explains better than his the worry that indeterminism constitutes the only difference between event-causal libertarianism and compatibilism. Finally, I consider potential objections to my account and reveal an important connection between the problem of enhanced control and the debate about the possibility of control over "passive omissions".

\section{Indeterminism as a Frankfurt-style intervener}

Central to Frankfurt's argument against the relevance of alternative possibilities to moral responsibility is the following example:

Suppose someone-Black, let us say-wants Jones to perform a certain action. Black is prepared to go to considerable lengths to get his way, but he prefers to avoid showing his hand unnecessarily. So he waits until Jones is about to make up his mind what to do, and he does nothing unless it is clear to him (Black is an excellent judge of such things) that Jones is going to decide to do what he wants him to do. If it does become clear that Jones is going to decide to do something else, Black takes effective steps to ensure that Jones decides to do, and that he does do, what he wants him to do. Whatever Jones's initial preferences and inclinations, then, Black will have his way... Now suppose that Black never has to show his hand because Jones, for reasons of his own, decides to perform and does perform the very action Black wants him to perform. (Frankfurt 2003/1969: 21-22)

This scenario supposedly supports the thesis that someone or something could deprive an agent of alternative possibilities while being totally irrelevant to the explanation of the agent's behavior. Because of Black, Jones could not have done otherwise, but that has no relevance

an irresistible desire, one does not originate the movement and the action in question, in the way necessary for being morally responsible. The same is the case when one acts under some kind of hypnosis or as a result of certain kinds of manipulation. In those cases one does not have control necessary for moral responsibility because one does not determine for oneself what one does, and one is not a true author of one's action. Thus, to have control necessary for moral responsibility one must satisfy the sourcehood condition, and to satisfy that condition certain factors must not play a role in the origination of one's action. What exactly those factors are, do they include determinism, what factors must play a role in the origination of one's action, and what role must they play for the sourcehood condition to be satisfied are difficult questions. Agent-causal libertarians, for instance, argue that factors which play a role in origination necessarily include the agent-causal power, while event-causal libertarians argue that those factors must involve only certain psychological events. For an in-depth analysis of the notion of sourcehood see Timpe (2012).

${ }^{8}$ Ishtiyaque Haji has offered yet another explanation of the worry that eventcausal libertarianism cannot provide an account of enhanced control (Haji 2013: 227-246). According to Haji, this theory cannot provide an adequate account of enhanced control because indeterminism diminishes control. However, I will not discuss this explanation here for two reasons. First, if the account of the problem of enhanced control I will present is correct, there is no need to appeal to the alleged control-diminishing effects of indeterminism to explain that problem. Second, Haji's explanation does not concern the worry that indeterminism is the only difference between event-causal libertarianism and compatibilism, and, explaining that worry is one of my main goals in this paper. 
to the explanation of Jones' action. For Jones performed the action on his own, for his own reasons.

Why is this important to the question about the relevance of alternative possibilities to moral responsibility? It is important, Frankfurt points out, because to be relevant to moral responsibility, something must bear on, or explain what actually happens, that is, explain how an action occurs (2006/1969: 23). This principle, together with the example above, leads to the conclusion that having alternative possibilities is irrelevant to moral responsibility. That is so because, if the example is coherent, that is, if Black's depriving Jones of alternative possibilities really has no relevance to the explanation of Jones' behavior, given this principle, Black's activity, and consequently, Jones' lack of alternative possibilities, are irrelevant to Jones' moral responsibility.

The fact that the principle in question seems intuitively very plausible, explains why the debate about Frankfurt's argument has been focused on the coherence of his example. ${ }^{9}$ However, the same principle, or more precisely, a version of the principle in which the phrase "moral responsibility" is replaced by the phrase "free will", explains why the problem of enhanced control is so difficult, and why the reference to alternative possibilities (the ability/opportunity to do otherwise) cannot solve it..$^{10}$ In the light of this principle, which I will call "E" (as a shorthand for the phrase "Explanatory Principle"), an alternative possibility (AP) is relevant to free will only if it plays some role in the production of an action (and thus explains the occurrence of that action). Thus, according to this principle, an AP that indeterminism provides according to even-causal libertarianism is relevant to free will only if it is relevantly different from Frankfurt's Black. But, is that the case? In my view, the answer is "no". For just like Black in Frankfurt's example, an indeterministic AP plays no role in the production of an event-causal libertarian action since it has no bearing on the reasons for which the action was performed, or on the powers exercised in its performance. ${ }^{11}$

${ }^{9}$ For an objection to this principle see Widerker (2003: 61-62), and Ginet (2003/1996: 82-83). I present and respond to the objection in question in section 4 .

${ }^{10}$ The following argumentation does not depend on the soundness of Frankfurt's argument (which I actually don't find convincing). It relies only on the plausibility of the principle in question (which I find very convincing). I don't find Frankfurt's argument convincing because I don't believe that a Frankfurt-style scenario-a scenario in which something deprives an agent of alternative possibilities without having an effect on what actually happens-is in fact possible. For this reason, I don't consider all the objections to Frankfurt's argument in this paper, but only those that question the relevant principle. For an analysis of the debate concerning Frankfurt's argument see Widerker and McKenna (2003: 1-13).

${ }^{11}$ Alternative possibilities that agents take into account when deliberating do bear on the reasons for which actions are performed. Thus, one might say that he or she chose to perform an action because he or she found the action better than an alternative action. However, the fact that an alternative is indeterministic adds nothing to the reasons one would otherwise have. The reasons we have for actions (the reasons we consider in deliberation, not the objective reasons) depend on what 
That is so because an indeterministic AP, on event-causal libertarian theory, has no (positive) effect on what actually happens (i.e. it doesn't provide new causal powers or new reasons for performing actions). ${ }^{12}$ Therefore, according to E, there is no relevant difference between an event-causal libertarian AP and Frankfurt's Black. In other words, E suggests that event-causal libertarian AP-s (the ability and opportunity to do otherwise) are irrelevant to free will. ${ }^{13}$

One could object, however, that, perhaps unlike Frankfurt's Black, an event-causal libertarian AP plays a role in the production of an action, although only a negative one: it implies that the causes of an action did not have to be its causes, that is, did not have to cause it. However, this does not make the AP in question relevantly different from Black (in the light of $\mathrm{E}$ ). For what makes $\mathrm{E}$ plausible is the notion that having free will means being a true or appropriate source of action. This notion, which is one of the central notions in the contemporary free will debate, implies that in order for something to be relevant to free will, that something must contribute to one's being an appropriate source of actions. And, to do that, it seems that the thing in question must contribute to one's being (more) involved in the production of one's actions. However, the fact that one's actions merely lack deterministic causes implies nothing about one's involvement in the production of those actions. ${ }^{14}$ Consequently, in the light of $\mathrm{E}$, the fact

we believe the alternatives are, not on their metaphysical properties.

${ }^{12}$ Robert Kane has argued that indeterminism contributes to sourcehood by making agents "the ultimate creators (or originators) and sustainers of their own ends and purposes" (Kane 1996: 23). However, as Randolph Clarke has noticed, this 'ultimacy' "opens alternatives but does not secure for the agent the exercise of any further positive powers to causally influence which of the alternatives left open by previous events will be made actual" (Clarke 2003: 108). I will discuss Kane's view in more depth in section 4.

${ }^{13}$ An anonymous reviewer has objected that "a libertarian (event-causal or otherwise) would reject" the principle E, and that "the principle just seems to be a rejection of libertarianism - and as such, seems to beg the question against Franklin." However, not all versions of libertarianism are incompatible with the principle E. The traditional (or standard) versions of agent-causal libertarianism, for example, are compatible with this principle. According to the theories of this type, freedom relevant to moral responsibility requires the power of agents to cause their actions qua agents - the agent-causal power. And having this power, or being able to exercise it, requires the absence of determination of agents' actions by prior events, that is, it requires the existence of indeterministic alternative possibilities. Now, since the agent-causal power explains how (free) actions occur in the agent-causal libertarian framework (they are exercises of, or results of the exercises of, the agentcausal power), and since the alternative possibilities contribute to the existence of that power, alternative possibilities also explain (free) actions in that framework (indirectly). Therefore, traditional agent-causal libertarian indeterministic alternative possibilities satisfy the principle E. For a useful discussion of agent-causal libertarianism see (Nelkin 2011: Ch. 4).

${ }^{14}$ Derk Pereboom has made a similar point: "We have already seen that by incompatibilist intuitions, an agent is not responsible for decisions determined by factors beyond his control. However, if these factors, rather than determining a 
that indeterminism bears on what happens negatively, makes indeterminism no different from Black, that is, it has no relevance to whether an action was performed freely.

Therefore, to understand why indeterminism seems irrelevant to free will (the control necessary for moral responsibility) in the eventcausal libertarian setting, we do not need to consider the relation between indeterminism and abilities in general, as Franklin suggests. It is sufficient to pay attention to the idea of sourcehood. When we do that, indeterminism appears irrelevant to event-causal libertarian free will just as Frankfurt's "counterfactual intervener" Black is irrelevant to Jones' moral responsibility. For just like Black in Frankfurt's example, indeterminism in the event-causal framework has no impact on the satisfaction of the sourcehood condition of freedom of the will.

In what follows, I argue that this account of the problem of enhanced control is superior to Franklin's because it explains better than his account the worry that indeterminism constitutes the only difference between event-causal libertarianism and compatibilism.

\section{No new abilities vs no difference in sources}

As I mentioned in the introduction, Franklin suggests that critics of event-causal libertarianism perceive indeterminism as the only difference between event-causal libertarianism and compatibilism because they cannot see how indeterminism could provide new abilities. But is it obvious that indeterminism could not provide new abilities in the framework of the event-causal theory of action? In my view, it is not so because it does not seem inconceivable that indeterminism could do that, and because it is plausible to think that changes in the laws of nature could affect our abilities.

Franklin believes that indeterminism cannot contribute to abilities because he believes that abilities supervene only on intrinsic properties of agents, i.e. the ways they are constituted, and because indeterminism (or determinism for that matter) does not bear on intrinsic properties (Franklin 2011: 694-5; 2018: 59-72). However, this view is problematic for two reasons. First, as I said, it is plausible to think that abilities depend on the laws of nature, and the laws of nature are not intrinsic to agents. Franklin could respond that abilities supervene on intrinsic properties holding the laws of nature fixed. However, it is not clear if this reply is legitimate in the present context because we clearly do not hold fixed the laws of nature in discussions of the effects of indeterminism on abilities (i.e. the effects of replacing deterministic laws with indeterministic laws or vice versa). Second, the existence of some of our abilities could depend on our environment in the way in which some of our dispositions depend on our environment. For ex-

single decision, simply leave open more than one possibility, and the agent plays no further role in determining which possibility is realized, then we have no more reason to hold him responsible than we do in deterministic case (Pereboom 2001: 48). 
ample, the existence of my key's disposition to open my lock seems to depend on the existence of my lock. That seems to be the case because the content of the disposition in question refers to my lock (Shoemaker 1980). Similarly, our abilities could depend on external things to which their contents are referring. ${ }^{15}$

The standard response to this argument is that my key does not have the disposition to open my lock, but rather the disposition to open locks of a kind to which my lock belongs (Molnar 2003). Franklin adopts a similar strategy when it comes to abilities. However, he admits that it is not obvious that this reply settles the dispute (Franklin 2018: 63).

Thus, it is not clear whether indeterminism could provide new abilities or not. Certainly, the appeal to intrinsic nature of abilities cannot settle this issue (at least, not in the current state of the debate). Consequently, when we focus on the relation between indeterminism and abilities in general, we don't see clearly that indeterminism is the only difference between event-causal libertarianism and compatibilism. For it is not obvious that indeterminism could not provide an agent with new abilities. However, when we compare the sources of event-causal libertarian and compatibilist actions we see immediately that indeterminism is the only difference between the types of agency in question. For the only difference between the sources of the event-causal libertarian and compatibilist actions is the absence of deterministic causes in the causal histories of the former.

That said, it is perhaps the case that some critics worry both about the alternative possibilities and sourcehood when it comes to the eventcausal libertarianism. They worry that adding indeterminism to other conditions postulated by this theory cannot produce any new powers relevant to freedom and moral responsibility. Nevertheless, defining the problem of enhanced control simply in terms of powers would be wrong. For even if one could show that indeterminism provides the ability to do otherwise in the event-causal framework, or the opportunity to exercise it, it would remain unclear how that ability or opportunity could enhance an agents control over his or her actions. For it is not clear how the combination of the ability and the opportunity in question could make an agent a more appropriate source of action. ${ }^{16}$

Let us now look at some potential objections to this account.

${ }^{15}$ Ferenc Huoranszki argues that abilities are extrinsic (2011: Ch. 3). However, Huoranszki also argues that our abilities do not depend on whether the laws of nature are indeterministic or deterministic (2011: Ch. 2).

${ }^{16}$ Although I have argued that it is not obvious that indeterminism could not provide the ability to do otherwise in the event-causal framework, I am inclined to think that it could not in fact do that. I believe that the ability to do otherwise is significant to free will. If indeterminism provided the ability to do otherwise it would surely enhance control. But, indeterminism in the event causal framework could not enhance control, for the reasons I present in this paper. Thus, by reductio ad absurdum, indeterminism cannot provide the ability to do otherwise in the relevant framework. 


\section{Objections}

I have argued that the focus on sources of event-causal libertarian and compatibilist actions allows us to see clearly that indeterminism cannot provide enhanced control. However, some philosophers find this claim problematic. They argue that the absence of deterministic causes in the causal histories of actions is significant because, in virtue of their absence, event-causal libertarian actions are not mere outcomes of the past and the laws of nature, and that such agents are not "pushed" or "manipulated" by the laws and the past. ${ }^{17}$

This response, however, does not help event-causal libertarianism. For to say that event-causal libertarian actions are not mere outcomes of the past and the laws of nature suggests that compatibilist actions are mere outcomes of the past and the laws. In other words, it suggests that compatibilist agents are not really agents but mere transmitters of external influences. However, this suggestion is misleading since, according to the event-causal theory of action, compatibilist agents are agents for the same reason for which event-causal libertarian agents are agents: their behavior is caused non-deviantly by the relevant mental states ${ }^{18}$ On the other hand, to say that, due to indeterminism, eventcausal libertarian agents are not pushed by the past and the laws of nature is useless to event-causal libertarians. For, as Randolph Clarke has pointed out, the fact that agents are not pushed by anything external, does not entail that they are more pushed by themselves (Clarke 2003: 106). Similarly, it is clear that the fact that they are not manipulated by the laws and the past (if "manipulation" just means causal determination) does not entail that they are more "manipulated by" or "controlled" by themselves.

${ }^{17}$ For the claim that, given determinism, "the agent is pushed by previous events into preferring and acting exactly as she does at each moment", see Ekstrom (2000: 190). For the claim that, given indeterminism, actions are not mere outcomes of the past and the laws of nature, see Haji (2013).

${ }^{18}$ An anonymous referee has observed that this "is, in effect, a one-line rejection of the so-called Consequence Argument (Van Inwagen), the point of which is precisely to show that under determinism (but not under indeterminism), actions are mere outcomes of the past and the laws." My response to this observation is that, if the point of the Consequence Argument were really what the referee claims it is, my argument would indeed constitute its refutation. For even under the assumption that determinism is incompatible with free will, it is plausible to make a distinction between an intentional action and something that merely happens to someone. For example, it is plausible to say that it is not the same thing if I move to another side of the street as a result of my intention to cross the street, and if that happens as a result of me being pushed by a strong wind (even if determinism precludes free will). For a similar point see (Huoranszki 2011: 13). However, there are other, more plausible, interpretations of the Consequence Argument that are immune to my "one-liner". One of those interpretations is an interpretation by Van Inwagen, according to which, the argument shows that under determinism, no one can do otherwise (Van Inwagen 1986: 68). 
An event-causal libertarian could respond to this that the absence of manipulation or pushing provides the enhanced control, not by itself, but in conjunction with the alternative possibilities that indeterminism provides. For instance, he or she could argue that the absence of manipulation and pushing, together with genuinely open alternatives, enhances agents' control by making agents the ultimate origins and true authors of their actions (Haji 2013: 239-40). However, it is not clear that being an ultimate origin or a true author in this sense implies enhanced control. For, again, it is not clear how the alternative possibilities open to event-causal libertarian agents by themselves, or in conjunction with the absence of manipulation and pushing, contribute to the satisfaction of the sourcehood condition of free will. ${ }^{19}$

To check this claim let us consider Robert Kane's view of free will, which is, arguably, the most sophisticated event-causal libertarian view. According to his view, the "ultimate responsibility" for actions derives from the existence of a special type of undetermined decisions which he calls the "self-forming actions" or "SFA-s" (he calls them so because in making such decisions we are supposedly setting our goals and shaping our characters). We make these decisions (assuming that indeterminism is true), when we are torn between conflicting motives (e. g. moral reasons and egoistic inclinations, or "present desires and long-term goals") and we have to make an effort to end the state of indecision. Decisions we make in such circumstances are rational (made for reasons) and voluntary, whether we end up pursuing moral reasons and long term goals, or egoistic reasons and our present desires (Kane 2007: 26). Because of that, Kane argues, indeterminism involved in SFA's, does not diminish our control over our actions, as some philosophers think. However, does it enhance our control? In my view, the answer is "no". The key thing to observe here is that the state of being torn between conflicting options, where one has to make an effort to overcome indecision, does not require indeterminism. An agent in a deterministic world could be in a psychological state identical to that of an agent performing an SFA. So, the old question arises again: how could mere indeterminism give one more control over his or her decisions? ${ }^{20}$

19 This is so because it is not clear how the combination of these factors could make an agent more involved in the origination of his or her actions. The factors in question do not give agents new powers to produce actions nor enable them to exercise the existing powers of that kind. In addition, they do not create new causes of actions or new reasons for actions. For the event-causal libertarian theory, unlike the traditional agent-causal theory, does not postulate the existence of any special power to originate actions (nor any reason or causal feature) that could not be possessed by an agent in a deterministic world.

${ }^{20}$ Daniel Dennett has made a similar point in his discussion of Kane's theory: "An indeterministic spark occurring at the moment we make our most important decisions couldn't make us more flexible, give us more opportunities, make us more self-made or autonomous in any way that could be discerned from inside or outside, so why should it matter to us? How could it be a difference that makes a difference? 
One could argue that to understand Kane's answer to this question we have to consider his view in more detail. One could point out that, according to Kane, determinism is not just a mere addition to other conditions of free will (in particular the effort to make a decision), because it is fused with the effort to make a decision (or choice): " $[t]$ he choice one way or the other is undetermined because the process preceding and potentially terminating in it (i.e. the effort of will to overcome temptation) is indeterminate" (Kane 1996: 128). Moreover, according to Kane, when making a free decision, the agent is making a dual (or double) effort; at the same time the agent is trying to make two incompatible decisions for which he or she has conflicting motivations. Thus, one could argue that Kane's theory explains how indeterminism produces a qualitative change in the origins of actions, thus contributing to the satisfaction of the sourcehood condition of free will.

However, the appeal to indeterminacy and doubling of effort does not explain how event-causal libertarian agents could be more involved in the production of their actions in comparison to their compatibilist counterparts. For, as Randolph Clarke has pointed out, indeterminate efforts explain free decisions only if they themselves are free. However, Kane's theory does not explain how indeterminism makes the later free (Clarke 2003: 89-90). Besides, it is questionable whether trying to make a specific decision (as opposed to trying to make some decision), and simultaneously trying to make an incompatible decision is psychologically possible, and whether it would aid or threaten freedom (Clarke 2003: 88). ${ }^{21}$

Now, one might wonder why indeterminism has to contribute to sourcehood in the event-causal framework in order to enhance control?

(Dennett 2003: 136) Consider also the following passage by Randolph Clarke: "But now, when we imaginatively compare this deterministic agent with another who differs only in that in the production of her decision there is the indeterminacy and indeterminism required by Kane, and we suppose that the former does not act with the freedom that would (given an ordinary moral capacity) suffice for responsibility, then we must say that the latter does not either. The required indeterminacy and indeterminism give us an ultimacy in the latter case that is not there in the former. But this ultimacy is wholly negative: it is merely the absence of any deterministic cause of the decision. It opens alternatives but does not secure for the agent the exercise of any further positive powers to causally influence which of the alternatives left open by previous events will be made actual" (Clarke 2003: 107-108). For a similar view see (Watson 2004a: 206).

${ }^{21}$ Mark Balaguer has developed a version of event-causal libertarianism that is also worth considering (see Balaguer 2010). However, in aspects key to the debate about the problem of enhanced control his account does not differ significantly from Kane's account. Like Kane's theory, his theory explains at best why indeterminism does not have to diminish control we have over our actions, but does not show how indeterminism could allow us to be more involved in the production of our actions. Surely, both of these theories deserve more attention, but I do not discuss them further here because I find another threat to my account more serious (the omissionsinvolving counterexamples to the principle E), and because I find the objections to Kane's view presented here very convincing. 
Couldn't a "compatibilist sourcehood" in conjunction with alternative possibilities provided by indeterminism be sufficient for enhanced control? The answer is "no" because event-causal libertarian alternative possibilities are irrelevant to free will according to the principle E. But, why should an event-causal libertarian accept that principle? There are two reasons for that. First, the principle $\mathrm{E}$ is intuitively very plausible. To see this, one just has to consider one's own intuitions about Frankfurt's Black. Second, there are no good arguments against E. One way in which some philosophers have tried to challenge it is by pointing out that things which do not help to explain why an action was omitted, may be relevant to whether that action was omitted freely. This challenge is based on the assumption that control over actions and control over omissions are essentially the same thing. In other words, some philosophers have tried to challenge $\mathrm{E}$ by making a parallel between actions and omissions. Consider in that context the following example:

Broken Phone: Smith witnesses a man being mugged outside his building. He knows he could easily dial 911, but, not wanting to be inconvenienced, decides to let sleeping dogs lie. Unbeknownst to Smith, however, and through no fault of his own, his telephone was not working. So he could not have called the police even if he had tried. ${ }^{22}$ (Capes and Swenson 2017: 974) The fact that the phone was broken made it impossible for Smith to call the police, but it played no role in Smith's decision to omit calling the police. Nevertheless, it seems clear that due to this fact, Smith is not responsible for his omission to call the police and did not freely omit doing it. For, in the given circumstances, it would clearly be wrong to demand of Smith to call the police and later blame him for not doing so, even though it would not be wrong to demand of him to try to call the police and blame him for failing to try. Therefore, the principle $\mathrm{E}$ appears to be false when it comes to omissions: it seems that something can be relevant to whether an action was omitted freely even though it did not actually play a role in the omitting. And that begs the following question: if freedom and responsibility are the same phenomenon when it comes to actions and omissions, is it really the case that something must play an explanatory role when it comes to actions to be relevant for freedom and responsibility?

To answer this question, it is important to notice that Smith's omission to call the police is not a basic omission. It is an omission which is

${ }^{22}$ This is a version of an example due to Van Inwagen (1983: 165-166). Neither Van Inwagen nor Swenson and Capes, however, use this example to challenge Frankfurt's version of the principle E, at least, not explicitly. Van Inwagen presents the example to show that Frankfurt-style examples do not generate the intuition that responsibility does not require alternative possibilities when it comes to omissions. Capes and Swenson use it to highlight the existence of luck in cases of this type, which in turn serves their defense of the 'flicker of freedom' response to Frankfurt's argument. On the other hand, Ginet (2003/1996: 82-84) and Widerker (2003: 61-62) explicitly consider similar examples as challenges to E, or more precisely, Frankfurt's version of E. However, I chose this example because of its simplicity. I will say a bit more about Ginet's and Widerker's examples in footnote 24 . 
a result of an action-a decision to omit. ${ }^{23}$ This is important because in discussions about free will and moral responsibility we are not interested primarily in non-basic actions and omissions, but in basic actions and omissions. For those discussions are focused on whether we have the control that constitutes free will, rather than on the scope of that control. And, having such control is possible only if we can have control over our basic actions or omissions. This raises another question: is a basic omission version of the above scenario, a scenario in which freedom and responsibility depend on some factor which does not actually play a role in 'bringing about' a basic omission, possible? To the best of my knowledge, nobody has yet presented such a scenario. ${ }^{24}$ And, it is hard to imagine a coherent scenario of that sort for two reasons. First, such an example would have to be a case of someone omitting

${ }^{23}$ With this in mind, it shouldn't be surprising that Smith's responsibility for the omission to call the police depends on factors that did not lead to his omission. For what we can control by our decisions depends on the cooperation of our environment, which may or may not influence our reasons for doing what we do. Moreover, what we do and perhaps what we omit doing by making decisions is a result of that cooperation. John Martin Fischer makes a similar point in the following passage: "So what the agent is morally responsible for depends on things which are quite extraneous to the agent-for instance the state of the telephone line. This might seem to introduce an unacceptable kind of 'moral luck' into our system of evaluating agents. But, whereas our way of specifying what Smith is responsible for depends on such factors, a certain moral evaluation of Smith does not. Smith would be equally morally blameworthy in either case, and it would seem appropriate to apply the same kind of punishment (or blame) in both cases. So, whereas a certain kind of moral luck applies to the specification of the content of moral responsibility, it does not apply to the extent or degree of blameworthiness, and it does not apply to the evaluation of agents" (Fischer 1986: 256).

${ }^{24}$ Ginet has presented an example which, at first sight, seems like such a scenario (2003/1996: 83-84). In his example a person omits an action without deciding to omit, and there is a device in her brain which monitors her neural processes ready to manipulate those processes if the person were to decide to perform the omitted action or begin to try to perform that action. This example is not relevant because it does not even attempt to show that the person has no alternative to basic omitting (omitting without deciding to omit). For, in Ginet's example, the device does not eliminate the possibility of the agent deciding to perform the omitted action. However, even if the device did do that, such an example would not be effective. For, even if something eliminated the possibility of an agent deciding not to omit the relevant action, if it played no role in the agent's omission, it would seem irrelevant to the agent's free will (control necessary for moral responsibility). Widerker, on the other hand, has showed that some factors which play no role in the explanation of our action or omission may be relevant to our moral assessment (2003: 61-62). Thus, he has showed that one's awareness that an alternative is morally better, or the existence of objective reason for performing or omitting an action (of which one may not be aware) may affect the person's responsibility (for non-basic omissions and actions) and blameworthiness without playing a role in the explanation of the relevant action or omission. This is an excellent observation. However, it is irrelevant to the principle $\mathrm{E}$. For the principle $\mathrm{E}$ concerns free will (control necessary for moral responsibility), and factors in question do not affect a person's control over his or her action or omission. Moreover, these factors also don't seem to affect one's responsibility but only the content of one's responsibility. 
to do something without deciding to omit (deciding to omit in such a case would also count as doing otherwise), and without being able to decide to omit due to the presence of a counterfactual intervener or mechanism (intervener or mechanism that does not actually intervene but would intervene under certain "counterfactual" circumstances). To show that the principle $\mathrm{E}$ is false when it comes to basic omissions, example of this sort would have to generate the intuition that the person in question is not responsible for the omission (and did not omit freely). However, if an omission was not caused by an external factor, it is hard to see why the person (which is otherwise free) did not omit freely (i.e. exercised control in omitting). Second, the idea that it is possible to have control over a basic omission (the idea of free basic omission) is problematic. For, as Michael Zimmerman (2017: 101) has observed, having control over something seems to entail having the ability to exercise control over that something. And, since an exercise of control is an activity, and basic omissions do not involve any activity ${ }^{25}$, it is not clear how one could be able to exercise (direct) control over a basic omission. Consequently, it is not clear how one could have control over such an omission.

A natural response to this argument is that having control over a basic omission does not actually require having the ability to exercise control over a basic omission, but only the ability (and opportunity) to perform the omitted action (or make a decision to perform that action).$^{26}$ To evaluate this response, consider the following scenario. You are on a freeway riding in a self-driving car programmed to go to a certain destination. You notice that your car is approaching an exit, and you have the ability to take the steering wheel and make a turn. However, you don't do that and do not make a decision to turn, and as a result you continue cruising down the freeway. If this happened, one could argue that your control over your omission in this situation consisted in your ability to make a turn (or to decide to make a turn). In addition, one could argue that the principle $\mathrm{E}$ is false because the ability to make a turn in this case was relevant to your control over the omission even though it played no role in the "origination" of the omission.

The problem with this response, however, is that it is actually hard to see how you could have had control over your omission in this scenario. To see why this is the case, notice that there seem to be only three possible explanations of your omission. First is that while deliberating about what to do, you missed the chance to turn, and thus lost the opportunity to decide. Second is that you couldn't really decide (like Buridan's ass) because you were torn by conflicting motives of equal strength. Finally, it could be that you were able to decide and were

${ }^{25}$ If an omission involved an activity such as a decision to omit or a trying to omit, it could be argued that it is not a basic omission, but an omission that derives from such an activity.

${ }^{26}$ Dana Key Nelkin and Samuel Rickless hold this view (see Nelkin and Rickless 2017: 120-132). 
fully aware of the timing, but instead of deliberating about what to do, you simply waited for an urge to turn to occur in you, and since that urge did not occur, you continued cruising. ${ }^{27}$ Given any of these explanations, you lacked (direct) control over your omission. Given the first explanation, that is so because, on that explanation, the above story does not even involve a basic omission. For, on that explanation, the omission was a result of an overextended deliberation about what to do (i.e. it was a result of an action). Given the second explanation, you also lacked control over your omission, for given that explanation, your omission resulted from an inability to decide, and, clearly, an omission cannot be under one's control if it results from one's inability to perform the omitted action. Finally, given the third explanation, you lacked direct control over your omission because it was not up to you whether you would perform or omit the relevant action, and that was the case because we do not have direct control over urges that may or may not occur in us. ${ }^{28}$

Thus, it is hard to see how one could have direct control over a basic omission in virtue of having the ability to perform the omitted action. Consequently, examples that supposedly involve such control are problematic and do not support the claim that the ability to do otherwise may be relevant to one's control over an omission (and on the assumption of equivalence between control over omissions and actions to actions) even though it plays no role in the explanation of the relevant omission. In addition, as we saw earlier, Frankfurt-style omission cases represent potential counterexamples to the principle $\mathrm{E}$ only when it comes to non-basic omissions. Therefore, instead of giving us reason to abandon the principle $\mathrm{E}$, considerations of omissions only give us reason to modify (or clarify) it by adding that it applies only to basic actions and omissions.

${ }^{27}$ Perhaps there is some other possibility that I cannot see currently. I invite you to consider this issue.

${ }^{28}$ Randolph Clarke says the following in support of the thesis that there are free basic omissions for which we can be responsible: “...when I refrain from touching the freshly painted object, I need not have decided not to touch it, and there need be no action at all that is my not touching it. Nevertheless, I might freely refrain from touching it. And it certainly seems that I can be responsible-perhaps praiseworthy - for not touching the object and messing up the paint job. In this case, its seems, we might have something - an intentional omission or refraining - that isn't an action of any kind and for which one can be directly responsible (2014: 108109). I find Clarke's view problematic for the reasons pertaining to the explanation of omission which I mentioned in the discussion of the car example in the text above. In particular, my worry is that Clarke's omission in his example is not free because his intention to omit either has its source in some earlier decision of his, or is something that just occurs in him-something over which he has no control. When we make decisions, in contrast, we are not just automatically following the urges that occur in us, we are considering reasons for and against certain action and consciously accepting or not accepting to act on certain motives. For a different objection to Clarke's view see (Zimmerman 2015: 366). 


\section{Conclusion}

When we consider carefully the claim that indeterminism constitutes the only difference between event-causal libertarianism and compatibilism, we see that the problem of enhanced control occurs not because of the worries concerning the abilities in general or the ability to do otherwise in particular, but because of the worries related to sourcehood. More precisely, we see that what generates the problem is the worry that, in the event-causal framework, indeterminism plays no positive role in the processes that lead to actions. In addition, we see that this fact about indeterminism represents a problem because of the principle $\mathrm{E}$, that is, because it seems necessary that something plays a role in the processes that lead to actions in order to be relevant to control. Some scenarios involving omissions suggest, at first sight, that $\mathrm{E}$ is in fact false. However, those scenarios either don't concern control necessary for moral responsibility, because they don't involve basic omissions, or seem to lack coherence because it is not clear that having control over basic omissions is possible.

\section{References}

Balaguer, M. 2004. "A Coherent, Naturalistic, and Plausible Formulation of Libertarian Free Will.” Noûs 38: 379-406.

2010. Free Will as an Open Scientific Problem. Cambridge: MIT Press.

Capes, A. J. and Swenson, P. 2016. "Frankfurt cases: the fine-grained response revisited." Philosophical Studies 174: 967-981.

Clark, R. 2003. Libertarian Accounts of Free Will. New York: Oxford University Press.

2014. Omissions: Agency, Metaphysics, and Responsibility. New York: Oxford University Press.

Davidson, D. 1980. Essays on Actions and Events. Oxford: Oxford University Press.

Dennett C. D. 2003. Freedom Evolves. New York: Viking.

Ekstrom, W. L. 2000. Free Will: A Philosophical Study. Boulder: Westview Press.

Fischer, M. J. and Ravizza, M. 2000. Responsibility and Control: A Theory of Moral Responsibility. Cambridge: Cambridge University Press.

Fischer, M. J. 1986. "Responsibility and Failure." Proceedings of the Aristotelian Society 86: 251-270.

Frankfurt, H. 2003. "Alternate Possibilities and Moral Responsibility." In M. McKenna and D. Widerker (eds.). Moral Responsibility and Alternative Possibilities: Essays on the Importance of Alternative Possibilities. Aldershot: Ashgate Press: 17-25, originally published in Journal of Philosophy 66 (1969): 829-39.

Franklin, C. E. 2011. "The Problem of Enhanced Control." Australasian Journal of Philosophy, 89/4: 687-706.

2018. Minimal Libertarianism: Free Will and the Promise of Reduction. New York: Oxford University Press. 
Ginet, Carl. 2003. "In Defense of the Principle of Alternative Possibilities: Why I Don't Find Frankfurt's Argument Convincing." In M. McKenna and D. Widerker (eds.). Moral Responsibility and Alternative Possibilities: Essays on the Importance of Alternative Possibilities. Aldershot: Ashgate Press: 75-90, originally published in Philosophical Perspectives 10 (1996): 403-17.

Haji, I. 2013. "Event-Causal Libertarianism's Control Conundrums." Grazer Philosophische Studien 88: 227-246.

Huoranszki, F. 2011. Freedom of the Will: A Conditional Analysis, New York: Routledge.

Kane, R. 1996. The Significance of Free Will. New York: Oxford University Press.

2007. "Libertarianism." In Four Views on Free Will, by J. M. Fischer, R. Kane, D. Pereboom, and M. Vargas. Oxford: Blackwell: 5-43.

Mele, A. 2006. Free Will and Luck. New York: Oxford University Press.

Molnar, G. Powers: A Study in Metaphysics. Oxford: Oxford University Press.

Nelkin, D. 2011. Making Sense of Freedom and Responsibility. New York: Oxford University Press.

O'Connor, T. 2000. Persons and Causes: The Metaphysics of Free Will. New York: Oxford University Press.

Pereboom, D. 2001. Living Without Free Will. New York. Cambridge University Press.

Shoemaker, S. 1980. "Causality and Properties." In P. van Inwagen (ed.). Time and Cause: Essays Presented to Richard Taylor. Dordrecht: Reidel: 109-135.

Taylor, R. 1966. Action and Purpose. Englewood Cliffs: Prentice-Hall.

Timpe, K. 2012. Free Will: Sourcehood and its Alternatives. London: Continuum.

Van Inwagen, P. 1983. An Essay on Free Will. Oxford: Clarendon Press.

Van Miltenburg, N. and Ometto, D. 2016. "The Libertarian Predicament: A Plea for Action Theory.” Synthese https://doi.org/10.1007/s11229-0161148-3. (online first). (196: 161-178).

Watson, G. 2004a. "Soft-Libertarianism and Hard-Compatibilism." In Agency and Answerability: Selected Essays. Oxford: Oxford University Press: 197-215. (First published in Journal of Ethics 3 (1999): 351-65.)

2004b. "Free Action and Free Will." In Agency and Answerability: Selected Essays. Oxford:

Oxford University Press: 161-196. (First published in Mind 96 (1987): 145-72.)

Widerker, D. 2003. "Blameworthiness and Frankfurt's Argument against the Principle of Alternative Possibilities." In M. McKenna and D. Widerker (eds.). Moral Responsibility and Alternative Possibilities: Essays on the Importance of Alternative Possibilities. Aldershot: Ashgate: 53-73.

Widerker, D. and McKenna, M. 2003. "Introduction." In M. McKenna and D. Widerker (eds.). Moral Responsibility and Alternative Possibilities: Essays on the Importance of Alternative Possibilities. Aldershot: Ashgate: 53-73. 
318 D. Čičić, Two Accounts of the Problem of Enhanced Control

Zimmerman, M. J. 2015. "Clarke on Omissions.” Criminal Justice Ethics 34(3): 361-371.

2017. "Omissions, Agency, and Control." In D. K. Nelkin and S. C. Rickless (eds.). The Ethics and Law of Omissions. New York: Oxford University Press. 